\title{
The prevalence of postoperative pain in a sample of 1490 surgical inpatients
}

Citation for published version (APA):

Sommer, M., de Rijke, J. M., van Kleer, M., Kessels, A. G. H., Peters, M. L., Geurts, J. M. W., Gramke, H. F., \& Marcus, M. A. E. (2008). The prevalence of postoperative pain in a sample of 1490 surgical inpatients. European Journal of Anaesthesiology, 25(4), 267-274.

https://doi.org/10.1017/S0265021507003031

Document status and date:

Published: 01/01/2008

DOI:

$10.1017 / \mathrm{S} 0265021507003031$

Document Version:

Publisher's PDF, also known as Version of record

Document license:

Taverne

Please check the document version of this publication:

- A submitted manuscript is the version of the article upon submission and before peer-review. There can be important differences between the submitted version and the official published version of record.

People interested in the research are advised to contact the author for the final version of the publication, or visit the DOI to the publisher's website.

- The final author version and the galley proof are versions of the publication after peer review.

- The final published version features the final layout of the paper including the volume, issue and page numbers.

Link to publication

\footnotetext{
General rights rights.

- You may freely distribute the URL identifying the publication in the public portal. please follow below link for the End User Agreement:

www.umlib.nl/taverne-license

Take down policy

If you believe that this document breaches copyright please contact us at:

repository@maastrichtuniversity.nl

providing details and we will investigate your claim.
}

Copyright and moral rights for the publications made accessible in the public portal are retained by the authors and/or other copyright owners and it is a condition of accessing publications that users recognise and abide by the legal requirements associated with these

- Users may download and print one copy of any publication from the public portal for the purpose of private study or research.

- You may not further distribute the material or use it for any profit-making activity or commercial gain

If the publication is distributed under the terms of Article $25 \mathrm{fa}$ of the Dutch Copyright Act, indicated by the "Taverne" license above, 


\title{
The prevalence of postoperative pain in a sample of 1490 surgical inpatients
}

\author{
M. Sommer ${ }^{*}, J_{*}$ M. de Rijke*, M. van Kleef*, A. G. H. Kessels ${ }^{\dagger}$, M. L. Peters ${ }^{\top}$, J. W. J. M. Geurts* \\ H.-F. Gramke*, M. A. E. Marcus* \\ University Hospital Maastricht, Departments of ${ }^{*}$ Anaesthesiology and Pain Treatment, ${ }^{\dagger}$ Clinical Epidemiology \\ and MTA, "Medical, Clinical and Experimental Psychology, Maastricht, The Netherlands
}

\begin{abstract}
Summary
Background and objective: To measure the prevalence of postoperative pain, an assessment was made of 1490 surgical inpatients who were receiving postoperative pain treatment according to an acute pain protocol. Methods: Measurements of pain (scores from 0 to 100 on a visual analogue scale) were obtained three times a day on the day before surgery and on days 0-4 postoperatively; mean pain intensity scores were calculated. Patients were classified as having no pain (score 0-5), mild pain (score 6-40), moderate pain (score 41-74) or severe pain (score 75-100). Results: Moderate or severe pain was reported by $41 \%$ of the patients on day 0 , $30 \%$ on days 1 and $19 \%, 16 \%$ and $14 \%$ on days 2,3 and 4 . The prevalence of moderate or severe pain in the abdominal surgery group was high on postoperative days $0-1(30-55 \%)$. A high prevalence of moderate or severe pain was found during the whole of days $1-4$ in the extremity surgery group (20-71\%) and in the back/ spinal surgery group (30-64\%). Conclusion: We conclude that despite an acute pain protocol, postoperative pain treatment was unsatisfactory, especially after intermediate and major surgical procedures on an extremity or on the spine.
\end{abstract}

Keywords: PAIN ACUTE AND POSTOPERATIVE; GUIDELINES; OUTCOME ASSESSMENT; QUALITY INDICATORS.

\section{Introduction}

During the past two decades, a great deal of attention has been paid to postoperative pain. Although the first suggestions were made in 1976 to introduce an 'analgesic team' within hospitals to improve postoperative pain management [1], it took until 1988 before the first official guidelines were published on the treatment of postoperative pain [2]. Rawal [3] advocated a 'stepwise approach' to postoperative pain, in which operations were classified as being minor, intermediate or major

Correspondence to: Michael Sommer, Department of Anaesthesiology, University Hospital Maastricht, PO Box 58006202 AZ Maastricht, The Netherlands. E-mail: mso@sane.azm.nl; Tel: +31 433875458; Fax: +31 433875457

Accepted for publication 15 October 2007 EJA 4090

First published online 6 December 2007 depending on the anticipated level of postoperative pain.

The question arises as to whether these guidelines and the subsequent introduction of acute pain teams have led to improvements in patient care in the postoperative period. According to the existing literature, there has been very little improvement in postoperative pain treatment over the past two decades [4-9]. However, it is difficult to compare the results between studies, due to differences in design, sample selection, sample size, pain evaluation assessment instruments, choice of pain intensity designation (mean, median or percentage) and especially due to poor descriptions of the findings. Postoperative pain is accepted as being a common clinical problem, but if more detailed information is required, for example, which surgical procedures 
are associated with the most postoperative pain, surprisingly few data are available in the literature. To improve pain protocols, it is important to have detailed knowledge.

Quite recently, the measurement of pain in a routine, standardized and easily comparable manner has become even more important in The Netherlands, because new Dutch healthcare regulations stipulate that the quality of the services must be made public by means of quality indicators. Searches have been made for quality indicators in different specialties and in many countries [10]. The purpose of these quality indicators, which are being developed by governments and researchers, is to measure and monitor the performance of healthcare providers. Patients and insurance companies can then choose hospitals on the basis of these indicators [11]. In 2004, a quality indicator for postoperative pain was formulated in The Netherlands as being the number of patients with a pain score of lower than 4 (on a scale of $0-10$ ) in the first $72 \mathrm{~h}$ after surgery divided by the number of patients evaluated. At present, however, only a small number of hospitals can publish complete data, because standardized pain registration has not yet been implemented at the majority of Dutch hospitals [12].

In preparation for the implementation of a standardized pain-registration programme, we wanted to know the proportion of patients who have unacceptable postoperative pain scores at our hospital, with 700 beds, 20000 surgical procedures per year and an acute pain management protocol that has been in use since 1995. Therefore, independent researchers measured the levels of postoperative pain in 1490 surgical inpatients and made an inventory of the most painful operation sites.

\section{Patients and methods}

A prevalence study was carried out on days $0-4$ postoperatively to obtain short-term follow-up data on surgery-related pain. After receiving approval from the institutional Ethics Committee, we enrolled all the consecutive patients admitted to the University Hospital Maastricht, The Netherlands, who were scheduled to undergo elective surgery between 1 February and 30 August 2003. The following surgical departments took part: general, plastic, ear nose and throat, facio-maxillary, neuro and thoracic surgeries, orthopaedics, ophthalmology, gynaecology and urology. Patients were excluded from the study if they were younger than $18 \mathrm{yr}$, had limitations of self-expression, visual dysfunction, insufficient knowledge of the Dutch language, or had been admitted for acute surgery, cardiac surgery or cesarean section, or had required postoperative ventilatory support. A total of 1975 subjects were eligible, of whom $1663(85 \%)$ agreed to participate. There were $140(8 \%)$ drop-outs for various reasons: postoperative ventilatory support $(n=50)$, the study became too burdensome for the patient $(n=32)$, complications followed by a second operation $(n=14)$ and miscellaneous $(n=44)$. The questionnaires from $33(2 \%)$ patients were not evaluable, because of too many missing data, which left 1490 evaluable patients. There were no significant differences in age and gender distributions between the non-responders and the participants.

After admission to the surgical ward, a trained research assistant explained the purpose and methods of the study to each eligible patient. Socio-demographic variables were recorded on all the patients who were willing to participate in the study. Pain intensities at rest and while coughing were scored 1 and $3 \mathrm{~h}$ postoperatively and at 9.00p.m. using a $100 \mathrm{~mm}$ visual analogue scale (VAS) anchored to 'no pain' and 'worst pain I can imagine'. On days 1-4 after the operation, pain was scored in a pain diary, three times a day. A research assistant visited all the patients once a day to give help if necessary, or three times a day if they were unable to fill in the diary themselves. The type of anaesthesia was not regulated by the study protocol. The choice of administration technique and analgesic agent was left to the individual anaesthetist and patient. (Agents used for general anaesthesia were propofol, etomidate, sufentanil, fentanyl, rocuronium, and vecuronium.) Patients who were discharged from hospital within 4 days postoperatively took their diary home and returned it to us in a special pre-paid envelope. Diaries that had not been returned within 14 days after surgery were chased up by contacting the patient by phone.

The perioperative pain protocol that has been used at our hospital since 1995 is based on the stepwise approach of acute pain treatment described by Rawal [3]. All the operations were categorized into three groups (minor, intermediate and major surgery) based on the anticipated level of postoperative pain. Subsequently, all the surgical procedures were categorized according to the anatomical site. This classification is also used in chronic pain patients and it has been recommended in the recent literature [13] (Table 1). Our preoperative protocol ensured that all the patients received paracetamol orally or rectally $1 \mathrm{~h}$ before the induction of anaesthesia.

In agreement with the prevailing protocol, postoperative pain after minor operations was treated with paracetamol $(1000 \mathrm{mg})$ four times a day, combined with non-steroidal anti-inflammatory drugs (NSAIDs) administered by the ward nurses. 
Rescue medication for moderate or severe pain (VAS $>40$ ) was piritramide intramuscularly (i.m.). Pain after intermediate operations was treated using the same protocol, combined with intravenous (i.v.) piritramide $(2-5 \mathrm{mg}$ ), which was repeated until the patient reported being pain-free. This was followed by i.m. piritramide $10-15 \mathrm{mg}$ six times a day. After major operations, piritramide was administered by intermittent i.v. infusion on an 'as needed' basis by the patient (patient-controlled analgesia, PCA), in line with the PCA protocol that has three dose levels of piritramide $(1.0,1.5$ and $2 \mathrm{mg}$ per bolus, with a lock-out interval of $5 \mathrm{~min}$ ). In many cases, major operations were conducted with a combination of general anaesthesia and epidural anaesthesia. Postoperatively, pain was treated by the continuous epidural infusion of bupivacaine $0.125 \%$ with sufentanil $1 \mu \mathrm{g} \mathrm{mL}^{-1}$.

After a post-anaesthesia care unit observation period of $2-4 \mathrm{~h}$, patients who had received minor and intermediate surgery returned to the surgical ward under the care of nurses who have experience with the postoperative pain protocol. Patients who underwent major surgery were followed by a specially trained postoperative pain nurse at least twice a day during the first 4 postoperative days. They enquired about pain at rest and after movement. If the pain score was higher than 40 and the patient had an epidural catheter for the continuous administration of analgesics, they administered a bolus of $5 \mathrm{~mL}$ and waited another $15 \mathrm{~min}$. After sufficient pain relief they increased the continuous analgesic level by $2 \mathrm{mLh}^{-1}$ and revisited the patient $2 \mathrm{~h}$ later. If there was no effect of bolus application, they contacted the anaesthetist who was supervising the pain team. When the patient was on PCA treatment, the first step was to find the reason for failure (bolus too low, lock-out time too long, other reason) and treat it. Then the effect was evaluated and after the pain score had decreased, they returned $2 \mathrm{~h}$ later to re-evaluate the pain treatment. If there was no improvement in the pain scores, they administered an extra bolus and increased the PCA bolus by one step according to the protocol and re-evaluated the patient $2 \mathrm{~h}$ later. Pain treatment was delivered in strict conformity with our protocol to every patient whether they were included in the study or not.

Data were analysed using descriptive statistics. Actual pain scores (VAS $0-100 \mathrm{~mm}$ ) on the day of the operation (POD 0) were used, measured at 1 and $3 \mathrm{~h}$ postoperatively and at 9.00p.m. Mean pain scores on the day of the operation and on postoperative days 0-4 (POD 1-4) were calculated, using the average of the three scores obtained from each individual on each of the days. As the pain diaries were sometimes incomplete, totals could vary from day to day. A mean pain score of higher than $40 \mathrm{~mm}$ on a VAS was regarded as being unacceptable. We defined 0-5 (VAS $0-100 \mathrm{~mm}$ ) as no pain, $6-40 \mathrm{~mm}$ as mild pain, $41-74 \mathrm{~mm}$ as moderate pain and $75-100 \mathrm{~mm}$ as severe pain $[8,14,15]$.

\section{Results}

Analyses were performed on the data from a total of 1490 evaluable patients. Table 1 shows the distribution of the operations subdivided into the anticipated level of pain and anatomical site. Patient characteristics are presented in Table 2. Slightly fewer male patients participated in this study than female patients ( $47 \%$ vs. 53\%). Forty-five percent of the patients were $60 \mathrm{yr}$ of age or older.

In Figure 1, VAS scores show that $1 \mathrm{~h}$ after the operation 357 out of 1361 evaluable patients (26\%) were suffering from moderate pain at rest (VAS 41-74; white section, first column) and 210 (15\%) were suffering from severe pain at rest (VAS $>75$; black top section, first column). Three hours after the operation and at 9.00p.m., these percentages were $26 \%$ and $10 \%$ for moderate and severe pain, respectively.

The figure shows also that 1 day after surgery $395(30 \%)$ out of the remaining 1306 patients reported moderate (white section, fourth column) or severe (black top section, fourth column) pain at rest (VAS $>40 \mathrm{~mm}$ ). On postoperative days 2, 3 and 4 , these percentages were $19 \%, 16 \%$ and $14 \%$, respectively.

The proportion of patients with moderate or severe pain increased while coughing in all anatomical subdivisions, except for the lower extremity (POD 1) (Fig. 2). Pain levels increased by $1 \%$ in the head/neck surgery patients to $21 \%$ in the upper abdominal surgery patients. In the lower extremity subdivision, pain while coughing decreased by $6 \%$.

Table 2 also shows the proportions of patients with a pain level of $>40$ at rest (VAS) in relation with their demographic and clinical characteristics. Significantly higher proportions of patients with moderate or severe pain were younger than $60 \mathrm{yr}$, were female and had received general anaesthesia only (day of operation). Surprisingly, from POD 1, the highest pain scores were found in the patients who had received general anaesthesia in combination with a loco-regional technique. Shortly after the operation, the patients in the intermediate surgery group had significantly more pain than the patients who had undergone minor or major surgery. On PODs $1-4$, the patients who had received 
Table 1. Surgical procedures subdivided according to anticipated postoperative pain level and anatomical site.

\begin{tabular}{|c|c|c|}
\hline $\begin{array}{l}\text { Anticipated } \\
\text { pain level }\end{array}$ & Anatomical site & Surgical procedure \\
\hline \multirow[t]{6}{*}{ Minor } & Head and neck $(n=295)$ & $\begin{array}{l}\text { Thyroidectomy, stapedectomy, tympanoplasty, petrosal bone and middle ear surgery, } \\
\text { cochlear implantation, middle ear inspection, middle ear reconstruction, auricle } \\
\text { reconstruction, nasal sinus inspection, endoscopy of pharynx, larynx, bronchus, } \\
\text { intracranial tumour surgery, craniotomy, eye surgery }\end{array}$ \\
\hline & Upper extremity $(n=10)$ & Peripheral vascular operations, wound toilet, sutures \\
\hline & Thorax, non-cardiac $(n=10)$ & Vascular operations, wound toilet \\
\hline & Lower abdomen/pelvis $(n=138)$ & $\begin{array}{l}\text { Vaginal urological procedures, cervix operation, abortion, hysteroscopy, operations of } \\
\text { male genital, endoscopic urological interventions e.g. TUR, cystic biopsy, urethra, } \\
\text { cystoscopy, plastic skin operations }\end{array}$ \\
\hline & Lower extremity $(n=20)$ & Plastic skin operations, peripheral vascular operations, wound toilet \\
\hline & Back/spinal $(n=13)$ & Urological neuromodulation, small plastic skin operations \\
\hline \multirow[t]{8}{*}{ Intermediate } & Head and neck $(n=85)$ & $\begin{array}{l}\text { Neck dissection, mouth and throat surgery, laryngectomy, pharynx and larynx surgery, } \\
\text { maxilla and mandibular surgery }\end{array}$ \\
\hline & Upper extremity $(n=39)$ & Orthopaedic hand and arm surgery \\
\hline & Thorax, non-cardiac $(n=31)$ & Oncological and plastic breast surgery \\
\hline & Upper abdomen $(n=69)$ & Fundoplication, duodenum surgery, cholecystectomy, nephrectomy \\
\hline & Lower abdomen/pelvis $(n=195)$ & $\begin{array}{l}\text { Surgery of vulva, ovary, adnexes, vaginal and abdominal hysterectomy, abdominal } \\
\text { endometriosis, closure of anus praeter, colorectal surgery, anal surgery, abdominal } \\
\text { vascular surgery, abdominal lipectomy, cystic resection, transvesical prostatectomy by } \\
\text { Hryntschak and radical prostatectomy }\end{array}$ \\
\hline & Lower extremity $(n=212)$ & $\begin{array}{l}\text { Plastic skin operations, orthopaedic surgery foot } / \mathrm{knee} / \mathrm{leg} / \mathrm{hip} \text {, amputation, peripheral } \\
\text { vascular surgery }\end{array}$ \\
\hline & Back/spinal $(n=63)$ & Plastic skin operations, spinal cord decompression with hemilaminectomy, discectomy \\
\hline & $>1$ site $(n=12)$ & Plastic breast + abdominal surgery, arm/hand and hip (fractures) \\
\hline \multirow[t]{5}{*}{ Major } & Upper extremity $(n=23)$ & Shoulder surgery (endoprothesis), clavicle surgery \\
\hline & Thorax, non-cardiac $(n=10)$ & Lobectomy \\
\hline & $\begin{array}{l}\text { Upper }+ \text { lower abdomen } \\
(n=171)\end{array}$ & $\begin{array}{l}\text { Hepatectomy, pancreatectomy, combination of different bowel surgery, aortic surgery, } \\
\text { extensive gynaecological surgery, combination of bowel and gynaecological surgery }\end{array}$ \\
\hline & Lower extremity $(n=60)$ & Total knee replacement \\
\hline & Back/spinal $(n=34)$ & Spondylodesis, spinal cord tumour resection, untethering \\
\hline
\end{tabular}

major surgery had the highest pain scores and this also applied to the patients whose operations had taken more than $2 \mathrm{~h}$.

Table 3 shows the distribution of patients with moderate or severe pain at rest (VAS $>40 \mathrm{~mm}$ ) per anatomical site and the anticipated pain level of the operation (minor, intermediate and major). The prevalence of moderate or severe pain in the abdominal surgery groups was high on the day of surgery and on POD 1 (30-55\%), except for the lower abdomen/pelvis surgery group (minor) (20\% and $11 \%)$. High prevalences of moderate or severe pain at rest were found during the whole of PODs $1-4$ in the upper/lower extremity group (20-71\%) as well as in the back/spinal group (30-64\%).

\section{Discussion}

We assessed the prevalence of postoperative pain in 1490 surgical inpatients who were receiving postoperative pain treatment according to an established acute pain protocol. Moderate or severe pain at rest was reported by $40 \%$ of the patients on the operation day. It then declined from day 2 until day 4 but, but almost $15 \%$ of all patients still had moderate or severe pain on day 4. Prevalence of moderate or severe pain at rest was high on the day of surgery and on POD $1(30-55 \%)$ in the abdominal surgery group. The highest prevalences of moderate or severe pain at rest during the whole of PODs $1-4$ were found in the patients who had undergone operations on the upper (intermediate and major) or lower (minor and major) extremity, or operations on the back/spine (intermediate and major), which had mainly comprised hemilaminectomy and spondylodesis.

In 1980, Cohen [7] found an incidence of $75 \%$ moderate or severe unrelieved pain. A survey by Owen and colleagues [16] $(n=259)$ in 1990 showed that $24 \mathrm{~h}$ after the operation, $75 \%$ were experiencing moderate to unbearable pain (verbal rating scale), while $72 \mathrm{~h}$ afterwards this was $65 \%$. No information was given about the anticipated pain level or anatomical site of the surgical procedures. Apparently, very few studies described the prevalence of postoperative pain in terms of anatomical site and anticipated pain level of the operation. In 1994, Oates and colleagues [5] reported a prevalence of $34 \%$ with moderate or severe pain 
Table 2. Distribution of patient characteristics in the total sample (column 2) and the number $(n)$ and proportion (\%) of patients with pain at rest $>40$ (VAS) on the day of the operation ( 1 and $3 \mathrm{~h}$ postoperatively (PO) and at 9.00p.m.) and with a mean pain at rest of $>40$ (VAS) 4 days postoperatively (PODs $1-4$ ) in relation with patient characteristics.

\begin{tabular}{|c|c|c|c|c|c|c|c|c|}
\hline & \multirow[b]{2}{*}{$\begin{array}{l}\text { Total } \\
\text { sample }\end{array}$} & \multicolumn{7}{|c|}{ Mean VAS $>40^{1}$} \\
\hline & & $\begin{array}{l}1 \mathrm{~h} \\
\text { postoperative }\end{array}$ & $\begin{array}{l}3 \mathrm{~h} \\
\text { postoperative }\end{array}$ & $\begin{array}{l}\text { POD }^{1} 0 \\
9.00 \text { p.m. }\end{array}$ & POD 1 & POD 2 & POD 3 & POD 4 \\
\hline & $n=1490$ & $n=1361$ & $n=1370$ & $n=1234$ & $n=1300$ & $n=1295$ & $n=1275$ & $n=1247$ \\
\hline & $n / \%$ & $n / \%$ & $n / \%$ & $n / \%$ & $n / \%$ & $n / \%$ & $n / \%$ & $n / \%$ \\
\hline \multicolumn{9}{|l|}{$\operatorname{Age}^{2}(\mathrm{yr})$} \\
\hline$<45$ & $374 / 25$ & $162 / 47$ & $140 / 40$ & $109 / 35$ & $112 / 35$ & $66 / 21$ & $47 / 15$ & $49 / 16$ \\
\hline $45-59$ & $449 / 30$ & $202 / 49$ & $166 / 40$ & $138 / 37$ & $134 / 33$ & $78 / 19$ & $80 / 20$ & $59 / 15$ \\
\hline $60+$ & $667 / 45$ & $203 / 34$ & $198 / 33$ & $189 / 34$ & $147 / 25$ & $97 / 17$ & $75 / 13$ & $59 / 11$ \\
\hline$P$-value ${ }^{3}$ & & $<0.001$ & 0.03 & 0.74 & 0.003 & 0.29 & 0.03 & 0.06 \\
\hline \multicolumn{9}{|l|}{ Gender } \\
\hline Male & $702 / 47$ & $222 / 34$ & $205 / 32$ & $166 / 29$ & $145 / 24$ & $93 / 15$ & $78 / 13$ & $62 / 11$ \\
\hline Female & $788 / 53$ & $345 / 48$ & $399 / 41$ & $270 / 41$ & $248 / 36$ & $148 / 22$ & $124 / 19$ & $105 / 16$ \\
\hline$P$-value ${ }^{3}$ & & $<0.001$ & $<0.001$ & $<0.001$ & $<0.001$ & $<0.001$ & 0.007 & 0.003 \\
\hline \multicolumn{9}{|l|}{ Type of anaesthesia } \\
\hline General & $1024 / 69$ & $473 / 51$ & $388 / 42$ & $304 / 37$ & $269 / 30$ & $175 / 20$ & $141 / 16$ & $113 / 13$ \\
\hline Locoregional (LR) & $270 / 18$ & $38 / 14$ & $68 / 26$ & $81 / 33$ & $58 / 25$ & $33 / 14$ & $31 / 14$ & $21 / 10$ \\
\hline General $+\mathrm{LR}^{5}$ & $196 / 13$ & $56 / 33$ & $48 / 27$ & $51 / 31$ & $66 / 38$ & $33 / 19$ & $30 / 17$ & $33 / 20$ \\
\hline$P$-value ${ }^{3}$ & & $<0.00$ & $<0.00$ & 0.18 & 0.01 & 0.14 & 0.6 & 0.01 \\
\hline \multicolumn{9}{|c|}{ Anticipated postoperative pain level } \\
\hline Minor & $486 / 33$ & $127 / 28$ & $116 / 26$ & $87 / 22$ & $71 / 16$ & $51 / 12$ & $39 / 9$ & $36 / 9$ \\
\hline Intermediate & $706 / 47$ & $326 / 51$ & $279 / 43$ & $245 / 41$ & $212 / 35$ & $122 / 20$ & $104 / 17$ & $75 / 13$ \\
\hline Major & $298 / 20$ & $114 / 44$ & $109 / 42$ & $104 / 43$ & $110 / 43$ & $68 / 27$ & $59 / 24$ & $56 / 23$ \\
\hline$P$-value ${ }^{3}$ & & $<0.001$ & $<0.001$ & $<0.001$ & $<0.001$ & $<0.001$ & $<0.001$ & $<0.001$ \\
\hline \multicolumn{9}{|l|}{ ASA score } \\
\hline I & $538 / 36$ & $219 / 43$ & $192 / 38$ & $155 / 34$ & $145 / 31$ & $82 / 17$ & $72 / 15$ & $57 / 13$ \\
\hline II & $684 / 46$ & $249 / 41$ & $229 / 36$ & $202 / 35$ & $186 / 30$ & $117 / 19$ & $91 / 15$ & $76 / 13$ \\
\hline III-IV & $268 / 18$ & $99 / 42$ & $83 / 37$ & $79 / 37$ & $62 / 29$ & $42 / 19$ & $39 / 18$ & $34 / 17$ \\
\hline$P$-value ${ }^{3}$ & & 0.64 & 0.84 & 0.83 & 0.83 & 0.79 & 0.77 & 0.40 \\
\hline \multicolumn{9}{|l|}{ Duration of operation } \\
\hline$<2 \mathrm{~h}$ & $1045 / 70$ & $393 / 40$ & $348 / 35$ & $306 / 35$ & $243 / 26$ & $143 / 16$ & $122 / 13$ & $104 / 12$ \\
\hline $2 \mathrm{~h}$ or more & $445 / 30$ & $174 / 46$ & $156 / 41$ & $130 / 37$ & $150 / 39$ & $98 / 25$ & $80 / 21$ & $63 / 16$ \\
\hline$P$-value ${ }^{3}$ & & 0.10 & 0.10 & 0.61 & $<0.001$ & $<0.001$ & $<0.001$ & 0.02 \\
\hline Total & $1490 / 100$ & $567 / 42$ & $504 / 37$ & $436 / 35$ & $393 / 30$ & $241 / 19$ & $202 / 16$ & $167 / 14$ \\
\hline
\end{tabular}

${ }^{1}$ On postoperative days (PODs) 1-4 values are mean values, this does apply to the values on the day of operation (POD 0 ).

${ }^{2}$ Mean \pm age was $56 \pm 15.5 \mathrm{yr}$.

${ }^{3} P$-values all derived from $\chi^{2}$ tests for differences in proportions between the age groups.

${ }^{4} 40$ patients in this group received 'peripheral blocks'.

${ }^{5}$ Five patients in this group received general anaesthesia + 'peripheral block'.

VAS: visual analogue scale.

$(V A S \geqslant 6)$ in a group of 199 patients who had undergone various surgical procedures. Svensson and colleagues [6] measured pain levels in 185 patients (surgical groups hip, knee, back, urological and gastrointestinal). At 4, 24, 48 and $72 \mathrm{~h}$ after the operation, moderate or severe pain (VAS $>40$ ) at rest was experienced by 39\%, 43\%, 27\% and $16 \%$ of the patients, respectively. These proportions were slightly higher than our findings. Unfortunately, no information was given about the postoperative pain level in relation with the surgical procedure.
In a review (2002) of data published on the incidence of moderate to severe or severe pain after major surgery, mean (95\% CI) incidences of moderate to severe pain and severe pain within the first $24 \mathrm{~h}$ were $30 \%(26-33 \%)$ and $11 \%(8-13 \%)$, respectively [8]. In the review, moderate to severe pain was defined as a VAS score of higher than 30/100, or a numerical score of more than 3/10. Severe pain was defined as a pain intensity score in excess of $70 / 100$ or $7 / 10$. In our study, $43 \%$ of the patients who underwent major surgery experienced moderate or severe pain on day 1 . This rate falls within the 


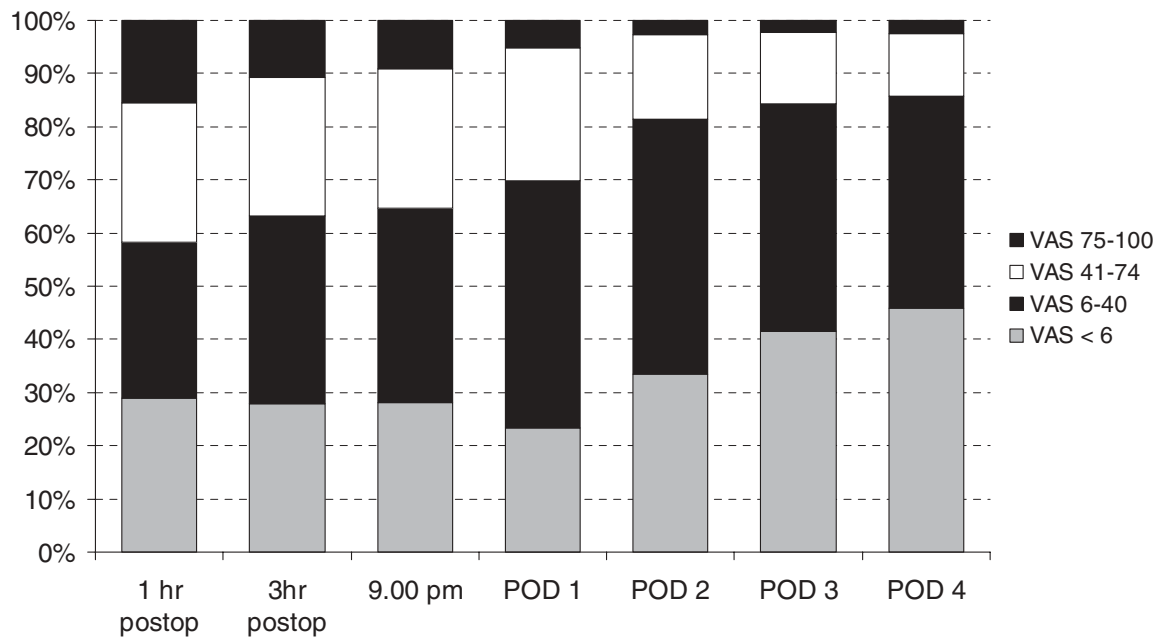

Figure 1.

Distribution of pain at rest (visual analogue scale) on the day of surgery (1 and 3 b postoperatively and at 9.00p.m.) and mean pain on postoperative days (PODs) 1-4.

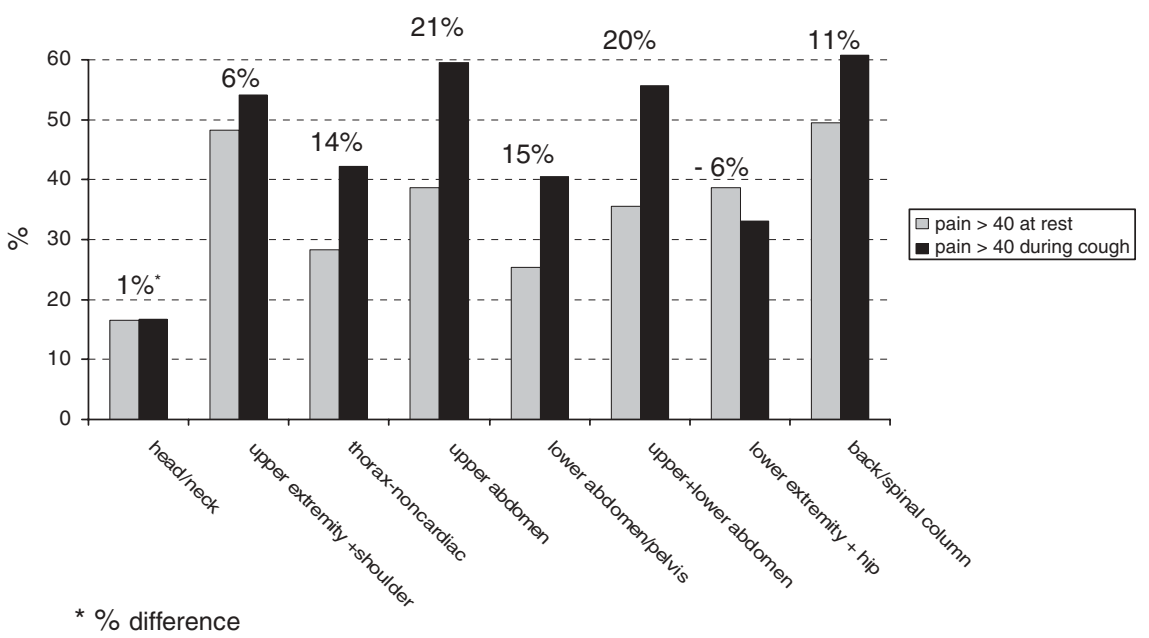

Figure 2 .

Distribution of patients with a mean pain at rest of $>40$ (visual analogue scale, VAS) and mean pain during coughing of $>40$ (VAS) on postoperative day 1 in relation with anatomical site.

95\% CI found by Dolin and colleagues [8], although we used a VAS cut-off point of $>40 \mathrm{~mm}$.

We also measured pain while coughing as an indicator of pain during movement. Although coughing was not the most ideal option, it was the most feasible manoeuvre in a large and heterogeneous group of surgical patients. Pain increased in all the surgical groups, except for the lower extremity. An increase in pain during movement is unacceptable, because it prevents the patient from being mobilized, or from breathing adequately. Some authors therefore recommended prophylactic treatment when pain levels increased beyond 40 on the VAS at former exercise sessions [17]. A decrease in pain intensity during coughing has been described before in a patient group that underwent hip operations [18]. The authors suggested that the decrease in pain could be due to distraction, which is a cognitive method of pain reduction. Another explanation for this phenomenon might be segmental inhibitory pathway activation [19].

In our study, the most painful surgical procedures (moderate pain: VAS 40-74 and severe pain: VAS > 75) were upper and lower extremity, thorax, abdomen and back/spinal column surgery. Upper extremity operations and thorax surgery with incision of the pleura were classified in the major surgery category, so advanced pain treatment had to 
Table 3. Number $(n)$ and proportion (\%) of patients with pain at rest $>40$ (VAS) on the day of surgery ( 1 and $3 \mathrm{~h}$ postoperatively and at 9.00 p.m.) and with a mean pain at rest of $>40$ (VAS) 4 days postoperatively (PODs 1-4) by anatomical site and anticipated postoperative pain level (minor, intermediate, major).

\begin{tabular}{|c|c|c|c|c|c|c|c|c|}
\hline \multirow[b]{4}{*}{ Anatomical site } & \multirow[b]{4}{*}{$\begin{array}{l}\text { Anticipated } \\
\text { postoperative pain level }\end{array}$} & \multicolumn{7}{|c|}{ Mean VAS $>40$} \\
\hline & & \multirow{2}{*}{$\begin{array}{l}1 \mathrm{~h} \text { PO } \\
n=1361\end{array}$} & \multirow{2}{*}{$\begin{array}{l}3 \text { h PO } \\
n=1370\end{array}$} & \multirow{2}{*}{$\begin{array}{l}\text { POD 0 } \\
9.00 \text { p.m. } \\
n=1234\end{array}$} & \multirow{2}{*}{$\begin{array}{l}\text { POD } 1 \\
n=1300\end{array}$} & \multirow{2}{*}{$\begin{array}{l}\text { POD } 2 \\
n=1295\end{array}$} & \multirow{2}{*}{$\begin{array}{l}\text { POD } 3 \\
n=1275\end{array}$} & \multirow{2}{*}{$\begin{array}{l}\text { POD } 4 \\
n=1247\end{array}$} \\
\hline & & & & & & & & \\
\hline & & $n / \%$ & $n / \%$ & $n / \%$ & $n / \%$ & $n / \%$ & $n / \%$ & $n / \%$ \\
\hline \multirow[t]{2}{*}{ Head/neck } & Minor & $81 / 30$ & $71 / 26$ & $49 / 21$ & $43 / 17$ & $28 / 11$ & $20 / 8$ & $19 / 8$ \\
\hline & Intermediate & $34 / 47$ & $21 / 29$ & $23 / 33$ & $13 / 17$ & $11 / 14$ & $9 / 12$ & $10 / 13$ \\
\hline \multirow[t]{3}{*}{ Upper extremity } & Minor & $2 / 20$ & $1 / 10$ & $2 / 25$ & $2 / 20$ & $1 / 10$ & $1 / 11$ & $1 / 11$ \\
\hline & Intermediate & $23 / 61$ & $20 / 54$ & $10 / 39$ & $15 / 46$ & $10 / 31$ & $10 / 32$ & $6 / 20$ \\
\hline & Major & $9 / 45$ & $8 / 38$ & $9 / 47$ & $12 / 71$ & $8 / 57$ & $7 / 47$ & $8 / 57$ \\
\hline \multirow[t]{3}{*}{ Thorax, non-cardiac } & Minor & $5 / 56$ & $5 / 63$ & $3 / 38$ & $3 / 33$ & $2 / 20$ & $2 / 22$ & $2 / 22$ \\
\hline & Intermediate & $19 / 70$ & $11 / 37$ & $8 / 33$ & $6 / 22$ & $4 / 14$ & $3 / 12$ & $3 / 12$ \\
\hline & Major & $5 / 50$ & $5 / 50$ & $3 / 33$ & $4 / 40$ & $4 / 44$ & $2 / 22$ & 0 \\
\hline Upper abdomen & Intermediate & $31 / 55$ & $24 / 44$ & $21 / 37$ & $22 / 39$ & $12 / 20$ & $11 / 19$ & $7 / 11$ \\
\hline \multirow[t]{2}{*}{ Lower abdomen/pelvis } & Minor & $25 / 19$ & $25 / 19$ & $22 / 20$ & $14 / 11$ & $14 / 11$ & $11 / 9$ & $9 / 8$ \\
\hline & Intermediate & $95 / 53$ & $77 / 41$ & $65 / 39$ & $61 / 36$ & $27 / 16$ & $24 / 14$ & $15 / 9$ \\
\hline Upper + lower abdomen & Major & $66 / 47$ & $55 / 38$ & $46 / 35$ & $53 / 36$ & $20 / 14$ & $22 / 15$ & $26 / 18$ \\
\hline \multirow[t]{3}{*}{ Lower extremity } & Minor & $7 / 37$ & $8 / 44$ & $7 / 39$ & $7 / 39$ & $6 / 32$ & $5 / 28$ & $5 / 26$ \\
\hline & Intermediate & $78 / 39$ & $89 / 43$ & $85 / 44$ & $64 / 35$ & $36 / 20$ & $30 / 17$ & $24 / 14$ \\
\hline & Major & $19 / 32$ & $21 / 39$ & $30 / 55$ & $25 / 50$ & $20 / 41$ & $14 / 30$ & $11 / 23$ \\
\hline \multirow[t]{3}{*}{ Back/spinal } & Minor & $7 / 58$ & $6 / 46$ & $4 / 36$ & $2 / 17$ & 0 & 0 & 0 \\
\hline & Intermediate & $39 / 64$ & $31 / 53$ & $28 / 56$ & $30 / 55$ & $22 / 39$ & $17 / 30$ & $10 / 19$ \\
\hline & Major & $15 / 52$ & $20 / 65$ & $16 / 55$ & $16 / 53$ & $16 / 49$ & $14 / 45$ & $11 / 34$ \\
\hline$>1$ site & Intermediate & $7 / 64$ & $6 / 50$ & $5 / 46$ & $1 / 11$ & 0 & 0 & 0 \\
\hline
\end{tabular}

VAS: visual analogue scale; PO: postoperatively; PODs: postoperative days.

be considered. However, a proportion of the breast surgery and back surgery patients had been included in the intermediate surgery group, in which they had mainly received i.m. bolus injections of opioids. This corresponds with one of the conclusions drawn in the review by Dolin and colleagues [8], namely that the highest percentage of patients with inadequate pain relief were receiving i.m. analgesics. The authors argued that when i.m. analgesia is administered using strict criteria, it can be an effective technique. However, the literature strongly suggests that this is not the case in clinical practice. It might be worthwhile to assign these patients to the major surgery group, but even the major surgery patients had high pain scores. There are several possible explanations for this. Firstly, a small proportion of the high levels of pain in the major surgery group might be explained by failure of the epidural catheters, which had an incidence of $5.7 \%$ [8]. Secondly, a proportion may have been due to suboptimal pain management on the hospital ward. Rawal [13] argued that the presence of an APS at a hospital does not automatically mean that all the patients receive good analgesia and are satisfied. Stamer and colleagues [20] conducted a survey on the organization and quality of acute pain services in Germany. They defined basic quality criteria: personnel assigned to provide APS, night and weekend policies, written pain management protocols and regular assessments and registration of pain scores at least once a day. It was found that $50 \%$ of German AP Services did not comply with these quality criteria. At our hospital, regular pain score assessments are only done on patients with a continuous epidural infusion or PCA. It is likely that the extension of standardized pain score documentation to all postoperative patients will contribute to more optimal pain management on hospital wards.

Thirdly, the acute pain protocol itself might have been insufficient if the estimate of anticipated postoperative pain was too low. In 2003, a multidisciplinary task force formulated postoperative pain guidelines after reviewing and evaluating the current literature on evidence-based knowledge, in conformity with the Agency for Health Care Policy and Research guideline published in 1993 [21]. All aspects of pain treatment were included, e.g. systemic oral, i.m., i.v., regional and non-medical techniques. In their recommendations, the anatomical site of the operation is an important aspect in decision-making concerning analgesic treatment. 
In a table, the choice of analgesia technique is correlated with the site of surgery or intervention. An algorithm to follow specific operations that incorporates the influence of the duration of surgery and the degree of tissue damage could make a valuable contribution to the standard pain protocol. In our subgroup analyses, we found significantly higher proportions of patients with moderate or severe pain among the younger patients $(<60 \mathrm{yr})$, females and patients who had received general anaesthesia only. This also applied to intermediate and major surgery and to operations that had taken more than $2 \mathrm{~h}$. These factors were exactly the same as those found by Kalkman and colleagues as being predictive for severe postoperative pain shortly after awakening. In addition, these factors have been identified as risk factors for chronic postoperative pain [22-24]. Besides the influence of various 'demographic' and general medical aspects, it has been proposed that individual psychological factors also influence postoperative pain, such as preoperative anxiety [25] and pain catastrophizing [26].

For a couple of surgical interventions, there are recommendations with respect to postoperative pain treatment given by the PROSPECT task force [27]. These recommendations which are based on a recent literature review are revised every 2 years. It is desirable that these recommendations will be part of the daily medical practise in each hospital. On the other hand, a lot more operations must be tackled by the task force in the future. Moreover, more data about somatic, psychological, demographic as well as genetic factors must be collected to get a deeper insight in the relation between surgical intervention and acute pain.

\section{References}

1. Anonymous. Postoperative pain [Editorial]. Anaesth Intensive Care 1976; 4: 95.

2. Rowlingson JC, Rawal N. Postoperative pain guidelines targeted to the site of surgery. Reg Anesth Pain Med 2003; 28: 265-267.

3. Rawal N. Postoperative pain and its management. In: Rawal N, ed. Management of Acute and Chronic Pain. London: BMJ Books, 1989.

4. Donovan M, Dillon P, McGuire L. Incidence and characteristics of pain in a sample of medical-surgical inpatients. Pain 1987; 30: 69-78.

5. Oates JD, Snowdon SL, Jayson DW. Failure of pain relief after surgery. Attitudes of ward staff and patients to postoperative analgesia. Anaesthesia 1994; 49: 755-758.

6. Svensson I, Sjöström B, Haljamäe H. Assessment of pain experiences after elective surgery. $J$ Pain Symptom Manage 2000; 20: 193-201.
7. Cohen FL. Postsurgical pain relief: patients' status and nurses' medication choices. Pain 1980; 9: 265-274.

8. Dolin SJ, Cashman JN, Bland JM. Effectiveness of acute postoperative pain management: I. Evidence from published data. BrJ Anaesth 2002; 89: 409-423.

9. Wheatley RG, Madej TH, Jackson IJ, Hunter D. The first year's experience of an acute pain service. $\mathrm{Br} J$ Anaesth 1991; 67: 353-359.

10. Idvall E, Hamrin E, Sjöström B, Unosson M. Quality indicators in postoperative pain management: a validation study. Scand J Caring Sci 2001; 15: 331-338.

11. Snyder C, Anderson G, Idvall E et al. Do quality improvement organizations improve the quality of hospital care for Medicare beneficiaries? Quality indicators in postoperative pain management: a validation study. JAMA 2005; 293: 2900-2907.

12. Wit Rd. Postoperative pain: a point of view (in Dutch). Ned Tijdschr Pijn Pijnbestrijding 2005; 24: 33-34.

13. Rawal N. Acute pain services revisited-good from far, far from good? Reg Anesth Pain Med 2002; 27: 117-121.

14. Collins SL, Moore RA, McQuay HJ. The visual analogue pain intensity scale: what is moderate pain in millimetres? Pain 1997; 72: 95-97.

15. Jensen MP, Chen C, Brugger AM. Interpretation of visual analog scale ratings and change scores: a reanalysis of two clinical trials of postoperative pain. J Pain 2003; 4: 407-414.

16. Owen H, McMillan V, Rogowski D. Postoperative pain therapy: a survey of patients' expectations and their experiences. Pain 1990; 41: 303-307.

17. Angster R, Hainsch-Müller I. Postoperatives schmerzmanagement [Postoperative pain management]. Anaesthesist 2005; 54: 505-531.

18. Fernandez E. A classification system of cognitive coping strategies for pain. Pain 1986; 26: 141-151.

19. Ong EL, Lim NL, Koay CK. Towards a pain-free venepuncture. Anaesthesia 2000; 55: 260-262.

20. Stamer UM, Mpasios N, Stuber F, Maier C. A survey of acute pain services in Germany and a discussion of international survey data. Reg Anesth Pain Med 2002; 27: 125-131.

21. Rosenquist RW, Rosenberg J. Postoperative pain guidelines. Reg Anesth Pain Med 2003; 28: 279-288.

22. Hannan EL, Magaziner J, Wang JJ et al. Mortality and locomotion 6 months after hospitalization for hip fracture: risk factors and risk-adjusted hospital outcomes. JAMA 2001; 285: 2736-2742.

23. Poobalan AS, Bruce J, King PM et al. Chronic pain and quality of life following open inguinal hernia repair. Br J Surg 2001; 88: 1122-1126.

24. Bruce J, Drury N, Poobalan AS et al. The prevalence of chronic chest and leg pain following cardiac surgery: a historical cohort study. Pain 2003; 104: 265-273.

25. Kalkman CJ, Visser K, Moen J et al. Preoperative prediction of severe postoperative pain. Pain 2003; 105: 415-423.

26. Pavlin DJ, Sullivan MJ, Freund PR, Roesen K. Catastrophizing: a risk factor for postsurgical pain. Clin J Pain 2005; 21: 83-90.

27. http://www.postoppain.org. Postoperative Pain Management, 2007. 